\title{
Organic farmers' motivations and challenges for adopting conservation agriculture in Europe
}

\author{
Marion Casagrande • Joséphine Peigné • Vincent Payet • Paul Mäder • F. Xavier Sans • \\ José Manuel Blanco-Moreno • Daniele Antichi • Paolo Bàrberi • Annelies Beeckman • \\ Federica Bigongiali • Julia Cooper • Hansueli Dierauer • Kate Gascoyne • Meike Grosse • \\ Juergen Heß • Andreas Kranzler • Anne Luik • Elen Peetsmann • Andreas Surböck • \\ Koen Willekens • Christophe David
}

Received: 12 February 2015 / Accepted: 12 October 2015

(C) Springer Science+Business Media Dordrecht 2015

\begin{abstract}
Conservation agriculture and organic farming are considered as promising sustainable agricultural system for producing food, while minimizing environmental impacts. Despite an increasing number of experimental data on organic conservation practices and various studies dealing with the adoption of conservation agriculture by farmers, none of those studies have specifically addressed conservation agriculture adoption under organic conditions in Europe. We carried out a survey with 159 farmers located in 10 European countries. These farmers
\end{abstract}

M. Casagrande $(\varangle) \cdot$ J. Peigné $\cdot$ V. Payet $\cdot$ C. David Department AGE, Université Lyon, ISARA-Lyon, 23 Rue Jean Baldassini, 69364 Lyon Cedex 07, France

e-mail: mcasagrande@isara.fr

P. Mäder · H. Dierauer

Research Institute of Organic Agriculture (FiBL), Ackerstrasse, 5070 Frick, Switzerland

F. X. Sans · J. M. Blanco-Moreno

Agroecosystems Research Group, University of Barcelona, Avda. Diagonal 643, 08028 Barcelona, Spain

\section{Antichi}

Centro di Ricerche Agro-ambientali "Enrico Avanzi”, Università di Pisa, Via Vecchia di Marina 6, 56122 San Piero a Grado Pisa, Italy

P. Bàrberi · F. Bigongiali

Institute of Life Sciences, Scuola Superiore Sant'Anna, Piazza

Martiri della Libertà 33, 56127 Pisa, Italy had applied at least two of the following conservation practices: (i) no-tillage, (ii) reduced tillage and (iii) green manures. Each farmer assessed socio-economic, agronomic and environmental motivations and problems for each conservation practice, using a Likert scale. For each conservation practice, we ranked motivations and problems and carried out a principal component analysis, followed by clustering to identify groups of farmers. Independent of the conservation practices, the most important motivations were related to soil fertility

\footnotetext{
A. Beeckman

Department of organic crop production, INAGRO, Ieperseweg 87, 8800 Roeselare, Belgium

J. Cooper · K. Gascoyne

UNEW, Nafferton Ecological Farming Group (NEFG), Newcastle University, Nafferton Farm, Stocksfield NE43 7XD, UK

M. Grosse · J. Heß

Department of Organic Farming and Cropping, University of Kassel, Nordbahnhofstr. 1a, 37213 Witzenhausen, Germany

A. Kranzler · A. Surböck

Research Institute of Organic Agriculture (FiBL) Austria, Doblhoffgasse 7/10, 1010 Wien, Austria

A. Luik · E. Peetsmann

Estonian University of Life Sciences, Kreutzwaldi 1, Tartu 51014, Estonia

K. Willekens

Plant Sciences Unit, Crop Husbandry and Environment, Institute for Agricultural and Fisheries Research (ILVO), Burg. Van Gansberghelaan 109, 9820 Merelbeke, Belgium
} 
preservation and challenges were mainly linked to crop management, machinery and yield performances. For all conservation practices, we identify three groups of farmers that shared the same type of motivations and challenges across Europe: "soil conservationists," "agro-technically challenged farmers," and "indifferent farmers." Soil conservationist farmers were strongly motivated by soil preservation and minimizing environmental impacts. Agro-technically challenged farmers mainly expressed agronomic problems and challenges. There were no clear effects of location or farm characteristics explaining these attitudes, but they depended on farmers' environmental concerns and beliefs. The study demonstrated that research priorities should address agronomic problems caused by the adoption of conservation practices in organic farming, weed control in particular.

Keywords Farmers · Conservation agriculture · Organic farming $\cdot$ Motivations $\cdot$ Challenges $\cdot$ Attitudes

\section{Introduction}

New sustainable agricultural concepts have been developed for producing food while protecting the environment. One of the most famous is conservation agriculture (CA) (Kassam et al. 2009; Hobbs et al. 2008), which relies on three principles: minimum or no soil disturbance, permanent organic soil cover and diversified crop rotation (http://www.fao.org/ag/ca/). Minimum soil disturbance is achieved through notillage or reduced tillage practices. Permanent soil cover is reached via green manures and mulches (living and/or dead) that protect the soil and improve its quality, while diversified crop rotation is based on the planting of different species in a time sequence in order to produce food, fodder and green manures, and in order to control pests and weeds while also optimizing nutrient uptake. Organic farming practices, which ban the use of synthetic fertilizers and pesticides, also aim at sustainable agricultural production. Organic farming also strongly relies on closed on-farm nutrient cycling, including biological nitrogen fixation and crop rotations, to support soil fertility by enhancing soil organic matter content (Leifeld 2012). Nevertheless, application of organic farming principles does not always imply improved soil fertility nor prevents erosion (Peigné et al. 2007) and environmental detrimental effects on soil have been raised (Leifeld 2012). The integration of conservation agriculture principles in organic farming should mitigate soil fertility challenges (Carr et al. 2013) and increase sustainability of organic farming production.

Currently, some organic farmers are adopting conservation agriculture principles in organic farming systems as an opportunity to address soil degradation problems (Teasdale et al. 2007). The combination of conservation agriculture with organic farming involves the rethinking of cropping systems and crop management. Depending on farmers' objectives, weed infestation, pedoclimatic conditions and equipment availability, management strategies differ in organic French farms (Lefèvre et al. 2012). Applying conservation principles in organic farming covers thus a range of management practices of variable intensity and combination of no-till, cover cropping and reduced tillage (Lefèvre et al. 2012). Indeed, reduced or no-tillage and cover crops lead to major modification of the system, especially with regard to weed control, fertilization and crop residue management (Peigné et al. 2007). Minimum soil disturbance practices are known to improve soil fertility under organic conditions (Berner et al. 2008; Carr et al. 2013) but might also pose a serious technical challenge (Peigné et al. 2007; Kuntz et al. 2013). For example, yields are expected to be lower (Peigné et al. 2007; Berner et al. 2008) and nitrogen mineralization in spring is retarded (Mäder and Berner 2011). Weed pressure is higher while direct non-chemical control methods are more difficult to apply (Peigné et al. 2007; Berner et al. 2008; Sans et al. 2011; Vakali et al. 2011; Carr et al. 2013). Indeed, if there is a cover crop during the period between two crops, application of false seedbed technique usually done in organic farming to limit weed infestation (Bàrberi 2002) is not possible anymore. On the other hand, reduced tillage or notillage prevents from ploughing which currently is the most common soil tillage technique used to manage weeds and incorporate organic surface residues in organic farming (Teasdale et al. 2007). Furthermore, some pest problems (e.g. slug) may be exacerbated under humid conditions (Berner et al. 2008).

Nowadays, there is an increasing number of experimental data on organic conservation practices (Mäder and Berner 2011) on the one hand. On the other hand, there are numerous studies dealing with the adoption of conservation agriculture by conventional farmers. A review of previous studies showed that the adoption rate of conservation agriculture depends on farmer and household characteristics such as age and education level (Knowler and Bradshaw 2007). Adoption also depends on farm 
biophysical characteristics such as size, soil and climate characteristics (Knowler and Bradshaw 2007; Lahmar 2010), as well as the social environment (e.g. extension services and networks) (Knowler and Bradshaw 2007; Lahmar 2010; Yiridoe et al. 2010). Moreover, other studies addressed the conversion of farmers to organic farming (Darnhofer et al. 2005). So far, none of those studies have specifically addressed conservation agriculture adoption under organic conditions in Europe, and little is known about cropping system management by organic farmers applying conservation agriculture

There is often a gap between experimental results and actual uptake by farmers (Giller et al. 2009; Schneider et al. 2009, 2012). To try to fill this gap, we conducted an exploratory study in ten European countries with organic farmers that had applied conservation practices (reduced tillage, no-tillage and/or green manure). This empirical study aims at answering the following questions:

Do the farmers feel the same type of motivations and problems when considering each conservation practice (no-tillage, reduced tillage and green manure) separately? Do the organic farmers really face the challenges of weed control and technical problems when adopting conservation agriculture as stated in previous studies? Are they mainly motivated by soil conservation as claimed by researchers?

Are there groups of organic farmers that share the same motivations and problems across Europe? What are the main factors that explain organic farmers' attitude when adopting conservation agriculture?

This empirical study aims at providing more insights on how and why European organic farmers do apply conservation principles. Identifying the problems they face aims at prioritizing future research challenges for supporting the development of conservation practices in organic farming.

\section{Material and methods}

The survey

The constitution of the sample

A survey was conducted in 2012 in ten European countries (Fig. 1): Estonia, Germany, UK, Ireland, Belgium,
France, Switzerland, Austria, Italy and Spain. The selected countries are partners of a European project on conservation agriculture in organic farming, leading to a wide range of pedoclimatic conditions and farming systems. The main objective of the survey was to capture the diversity of organic farmers applying conservation practices at a European scale. However, as there is no existing specific network of organic farmers using conservation practices, the farmers were contacted using organic agriculture or conservation agriculture networks (agricultural magazines, internet forums, local organizations). Therefore, the sample was not exhaustive, not all European countries were surveyed, and only farmers who heard about the study or were already known by the partners were surveyed. This exploratory study aimed at covering the diversity of organic farmers applying conservation agriculture and not their representativeness at European scale.

The main selection criteria were that the interviewed farmers followed Organic European Regulation (No 834/2007) and had applied at least two of the three following management practices: green manure, notillage and reduced tillage. The interviewed farmers could have applied them to all or part of their arable crops. In this study, we defined no-tillage (also known as zero tillage) as a conservation tillage practice in which the crop is sown directly into the soil not tilled since the harvest of the previous crop. Reduced tillage refers either to an inversion tillage method at a depth considerably shallower than the conventional ploughing depth, or to a non-inversion method such as chisel ploughing. In our study, we called green manure any crop that is grown primarily or solely for the purpose of soil protection and improvement, including the following: increasing soil $\mathrm{N}$ supply to the subsequent crop and soil organic matter, regulating the populations of pests and diseases, reducing competition from weeds in subsequent crops and minimizing soil erosion.

\section{The questionnaire}

To cover the diversity and establish groups of farmers, we chose a questionnaire with closed-ended questions. Such a questionnaire allowed us to (i) homogenize and translate the answers of farmers speaking ten different languages without interpretation error and (ii) use statistical analysis as multicomponent analysis, to reveal groups of farmers with similar behaviour or attitude. This type of survey and the related statistical analysis 


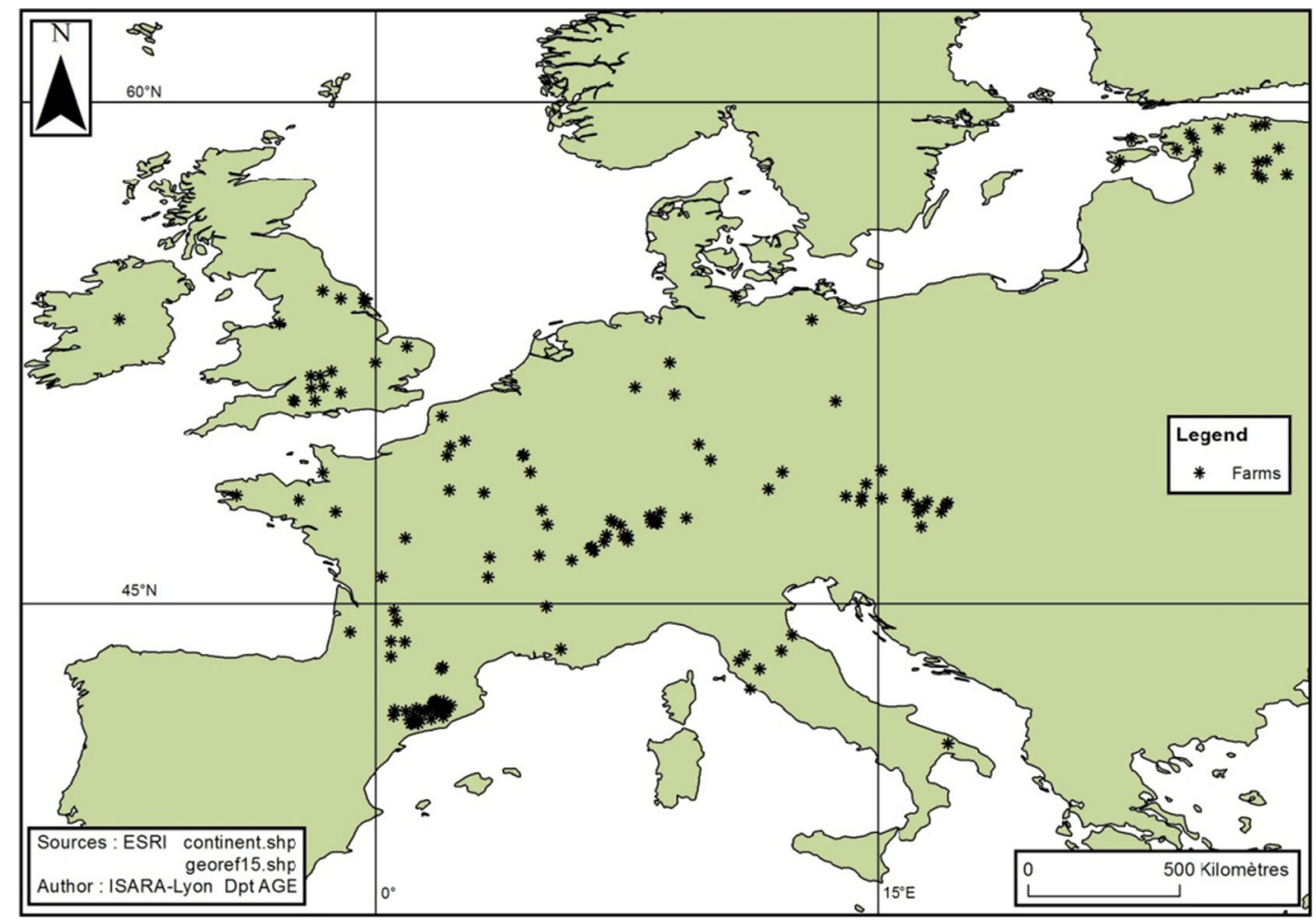

Fig. 1 Map of interviewed farmers throughout Europe

were proposed by Greiner et al. (2009). Therefore, the questionnaire was translated into local languages by partners, and forms were filled out by an advisor or a researcher during farmers' interviews (either by phone or during individual meetings).

The questionnaire was divided in two sections: (1) farm description, and (2) motivations and problems associated with adopting conservation agriculture practices (tested motivations and problems for each practice are available in Fig. 2). In part 1, we collected information related to the farm and its environment (e.g. farm size, geographical coordinates, soil types and climatic conditions) and the socio-economic characteristics of the farm (e.g. principal type of farming, years since conversion to organic farming, age of the farmer, his/ her sources of information on organic farming and conservation agriculture). Moreover, farmers described their cropping systems (e.g. list of crops, crop areas dedicated to each crop, use of irrigation and crop rotation), the fertilization management (e.g. type and amounts of nitrogen) and, in cases of mixed farms, livestock system data (e.g. livestock type and units, and use of manure). In part 2, the focus shifted towards the motivations and problems encountered by farmers in their adoption of conservation agriculture practices. We first asked what were the conservation practices applied on the farm (no-tillage and/or reduced tillage and/or green manures) and when they had started to apply them (i.e. the number of years of experience with the practice). For each applied practice, they rated 12 proposed motivations and 12 proposed problems according to a Likert scale, ranging from 1 (not important at all) to 5 (extremely important) (2, of minor importance; 3 , moderately important; 4, very important). The motivations and problems in the suggested lists encompassed socio-economic, technical, agronomic and environmental themes (Fig. 2) and were inspired by previous studies (Knowler and Bradshaw 2007; Lahmar 2010; Lefèvre et al. 2012; Soane et al. 2012). Indeed, conservation agriculture aims at addressing the problems of soil degradation (Giller et al. 2009) by improving soil organic matter content, limiting soil erosion and improving soil structure and fertility. We thus proposed motivations related to soil fertility such as "increasing organic matter content in the soil" or "improving soil structure" (Fig. 2). Conservation agriculture is also expected to limit 
(a)

improving soil biological quality
improving soil structure
increasing organic matter
reducing costs
improving biodiversity
minimizing environmental impacts
limiting erosion crust formation
technical/innovative challenge
enhancing residue mineralization
improving yields
limiting weeds, pests and diseases
advice from network/neighbour

(b)

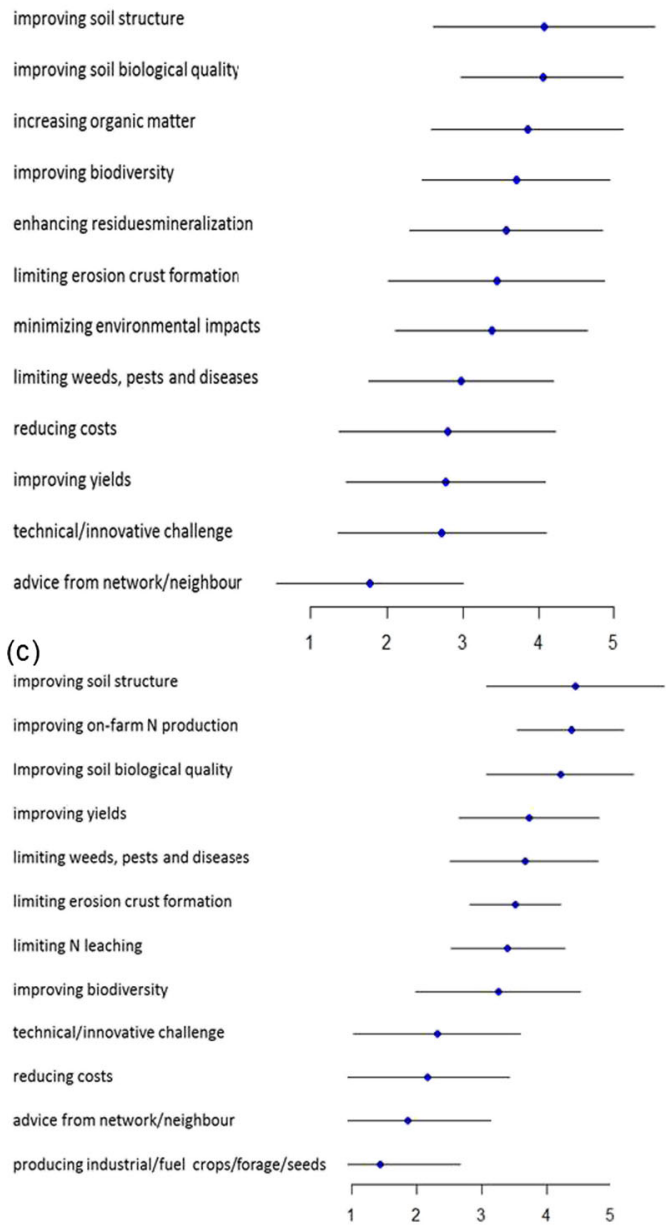

Fig. 2 Ranking of the means of Likert scale values of motivations (left) and problems (right) for a the 40 interviewed organic farmers using no-tillage, b the 138 interviewed organic farmers using reduced tillage and $\mathbf{c}$ the 123 interviewed organic farmers using

time, labour and fuel requirements and increase yields while preserving soil quality (Derpsch et al.

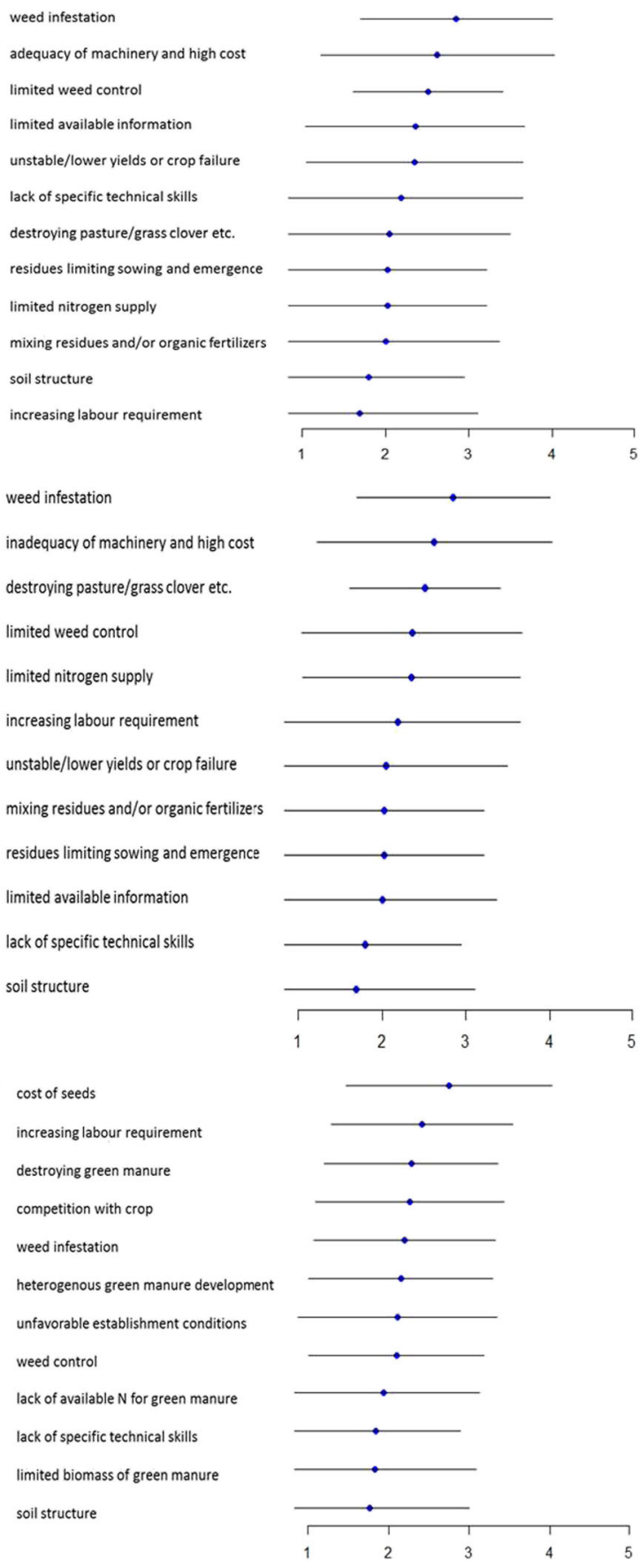

green manure (1: not important at all, 2: of minor importance, 3 : moderately important, 4 : very important, 5 : extremely important). Lines represent the standard deviation

2010). We thus proposed motivations such as "reducing costs" or "improving yields" (Fig. 2). 


\section{The interviewed farmers}

We interviewed 159 organic farmers: 17 farmers in Estonia, 10 farmers in Germany, 16 farmers UK, 1 farmer in Ireland, 9 farmers in Belgium, 31 farmers in France, 19 farmers in Switzerland, 16 farmers in Austria, 7 farmers in Italy and 33 farmers Spain (mainly in Cataluña). The objective was to interview around 30 farmers per country. We reached our objective only in two countries due to the difficulty to find organic farmers applying conservation agriculture principles. In terms of geographical coordinates, 80 farmers are located in north of $45^{\circ} \mathrm{N}$ and west of $17^{\circ} \mathrm{E}, 29$ are located in north of $45^{\circ} \mathrm{N}$ and east of $17^{\circ} \mathrm{E}$ and 50 farmers in south of $45^{\circ} \mathrm{N}$.

An arable crop production system was the main principal type of farming for $45 \%$ of the interviewed farmers. A livestock production system and vegetable production system were the main farming types for 14 and $8 \%$, respectively, of interviewed farmers. Arable crops are often combined with other productions: $14 \%$ of the interviewed farmers combined arable crops and livestock, $6 \%$ combined arable and perennial crops and $4 \%$ combined arable and vegetable crops. The mean size of the farms was 125 ha, with a high coefficient of variation ( $80 \%)$ and a median value of 66 ha. Thirtyeight percent of farms had a land surface of less than 50 ha (small farms), $22 \%$ of farms ranged from 50 to 100 ha (medium farms) and $40 \%$ of farms were over 100 ha (large farms).

Twenty-four percent of the interviewed organic farmers were younger than 40 years old (young farmers), $64 \%$ were between 40 and 60 years old (middle aged farmers) and $12 \%$ were over 60 years old (senior farmers). The majority of interviewed farmers had converted to organic farming during the past 20 years ( $31 \%$ in the last 10 years, and $45 \%$ from 10 to 20 years ago). Only $8 \%$ of farmers (or their parents) had converted their land more than 30 years ago, and $17 \%$ from 20 to 30 years ago. The main sources of information on organic farming were, first, the specialized literature (newspapers, journals); then, Internet and the networks they belong to; and lastly, advisors and courses. Farmer unions were almost never quoted. We found the same ranking concerning sources of information on conservation agriculture, except that their first source of information came from their own experience. Networks refer to local or national farmer organizations that are dedicated either to organic farming or conservation agriculture. The mean number of sources of information for organic farming was 1.98, whereas it reached only 1.44 for conservation agriculture.

\section{Statistical analysis}

We first analyzed the farmer sample with simple descriptive statistics. Then, for each conservation practice, we ranked the motivations and problems according to their average Likert scale value. Items measured using Likert-type scales were treated as continuous variables (Greiner et al. 2009). Then, for each practice, we carried out a principal component analysis (PCA) combining motivation and problem data sets. Second, we tested if supplementary variables could be related to the main components. Finally, we carried out a hierarchical cluster analysis on principal components (HCPC). Missing values were replaced by the column mean (Lê et al. 2008).

The objective of the PCA analysis was first to condense the variability between the individuals (farmers) in a few synthetic components, in order to facilitate the identification of groups of individuals. Moreover, PCA summarizes the relationships between the variables (here motivations and problems). PCA calculates the correlation between each variable and the coordinates of the individuals on the newly computed components (Pearson's $r, P<0.01$ ). The correlation coefficients are pairwise calculated for all the variables with each component and sorted according to their significance to identify the variables that best describe the components. ${ }^{1}$

In order to help interpret the components, we tested supplementary variables that were not used to build the principal components. We computed and tested for statistical significance of the relationship between the supplementary variables and components 1 and 2 . In the case of continuous supplementary variables, we used coefficients of correlation (Pearson's $r, P<0.05$ ), and in the case of categorical supplementary variables, we computed the estimated effect of each modality (tested with $t$ test, with alpha $=0.05$ ). We tested structural variables: (i) continuous ones such as age of farmer, number of years since organic conversion, number of years of experience with each practice, number of sources of

\footnotetext{
${ }^{1}$ Anyone interested in the detailed data or other materials such as the R scripts can e-mail the corresponding author.
} 
information for organic farming, and number of sources of information for conservation agriculture, and (ii) categorical ones, i.e. principal type of farming and network as a source of information for conservation agriculture and organic farming. We also tested continuous geographical variables such as altitude, precipitation, geographical coordinates and the country as categorical geographical variable.

Finally, the five first principal components were submitted to clustering, to determine groups of farmers sharing the same motivations and problems. The optimal number of groups was determined by means of the gain of within-cluster inertia. For each practice and group, we identified the motivations and problems, which characterize the group (V-test, $P<0.05$ ) (Lê et al. 2008). This is an equivalent to a $t$ test for the comparison of the group mean in relation to a given overall mean of the sample

All statistical analyses were conducted in R (v2.15.1) (R Core Team 2012) with the packages FactoMineR (Lê et al. 2008) and ade4 (Thioulouse et al. 1997).

\section{Results}

Conservation agriculture practices used

by the interviewed farmers

Reduced tillage was used by $89 \%$, green manure by $74 \%$ and no-tillage by $27 \%$ of the interviewed farmers. The combination of reduced tillage and green manure was used by $63 \%$ of the farmers. Only $19 \%$ of the farmers combined no-tillage and green manure. Farmers' experience with each practice was varying: No-tillage has been applied on average for 5.25 years (SD 4.7 years), reduced tillage on average for 19 years (SD 13 years) and green manure on average for 16 years (SD 9 years). The organic farmers of the sample were thus more experienced with reduced tillage and green manure compared with no-tillage.

On the one hand, green manure applications were more frequent in the north-western and north-eastern part of Europe where, respectively, 83 and $96 \%$ of farmers use green manure, compared to only $48 \%$ of farmers in southern Europe. On the other hand, the number of farmers applying reduced tillage in the southern part of Europe was higher than in the northern part. For example, almost all farmers ( $98 \%$ of the sample) applied reduced tillage in the southern part of Europe compared to 92 and $66 \%$ in the north-western and north-eastern parts of Europe, respectively. The rate of farmers applying no-tillage in the southern part of Europe was also higher than in the northern part: $34 \%$ in the south compared to 25 and $21 \%$ in the northwestern and north-eastern parts of Europe, respectively. These results showed that in cool, humid areas of Europe, non-inversion tillage techniques are less applied than in southern Europe. This is probably due to higher yield loss risks that could be induced by several factors, such as weed competition, soil compaction, or delayed mineralization (Soane et al. 2012). Conversely, in southern Europe, water limitations and high temperature make green manure establishment difficult, explaining its lower frequency of application (Soane et al. 2012).

\section{Ranking of motivations and problems}

The main motivation for using no-tillage was the improvement of soil fertility (biological soil quality, soil structure and organic matter content, Fig. 2). Reducing cost was the fourth motivation. The main problem was weed infestation, and as a result, weed control was also quoted as a key challenge (Fig. 2). Farmers also pointed out the lack of information and adapted machinery for no-tillage in organic farming. Technical problems such as residue and nitrogen management were less important.

Like no-tillage, the main motivation for using reduced tillage was the improvement of soil fertility (soil structure, biological soil quality and organic matter content, Fig. 2). The main problem was weed infestation even if reduced tillage can help better control weeds compared to no-tillage. Farmers pointed out the problem of inadequate machinery and cost for applying reduced tillage in organic farming. A technical problem of pasture or green manure destruction was also highlighted (third problem among 12).

The main motivation for using green manure was also the improvement of soil fertility (soil structure, on-farm nitrogen and biological soil activity, Fig. 2). Improving yields and limiting weeds, pests and diseases followed (fourth and fifth motivations among 12). The main problems were the cost of seeds and labour requirements. Farmers also pointed out technical and agronomic problems when destroying the green manure, as well as weed competition, and competition between main crop and green manure. Some farmers (5 out of 123) also spontaneously cited support programs and 
policies or cross-compliance directives because green manure application is part of agri-environmental measures in the surveyed countries.

Figure 2 shows that the variability of responses related to problems is higher (larger standard deviation values) than the variability of responses related to motivations. Moreover, the average rating of motivations is generally higher than that of problems. Indeed, the highest motivation value is always over 3 (moderately important), while the highest problem value is always under 3. This shows that the interviewed organic farmers feel more concerned by motivations than problems when rating conservation practices. As the selected farmers had applied at least two conservation practices, we consider them to be quite enthusiastic farmers concerning CA. The greater variety of answers related to the problems than the motivations shows that they are more likely to have different perceptions of their problems compared to the motivations. This might be explained by the large range of different conditions (climate, soil, policies, etc.) across the ten surveyed countries. When comparing the rating for reduced and no-tillage (Fig. 2), we show that major motivations and problems and their rankings are similar for both practices.

\section{Farmers' groups}

For each practice, a two-component model was found to provide a good fit, with more than $30 \%$ of the variance explained (Figs. 3, 4 and 5). All the correlated variables $(P<0.01)$, i.e. motivations and problems, that explain components 1 and 2 were identified and sorted according to their correlation with the components. For each practice, the maximization of the inertia gain when clustering provided three groups. For each practice, the significant variables (motivations and problems) of each group were identified with a V-test $(P<0.05)^{2}$.

\section{Component 2}

Soil fertility motivations

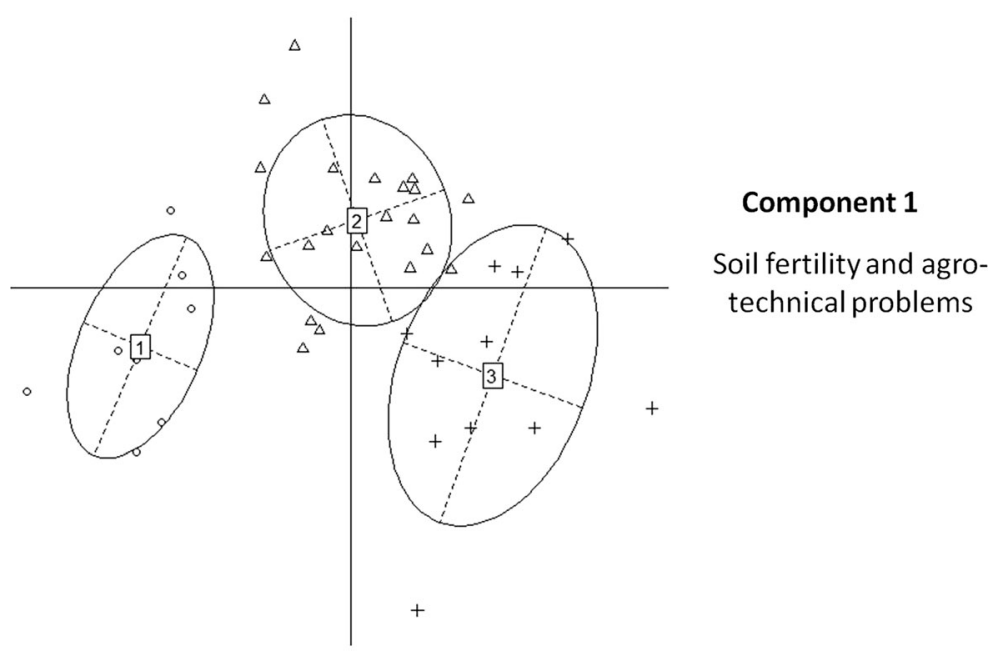

Agro-technical problems

Fig. 3 Distribution and grouping of the 40 farmers using notillage on the PCA map. Legend: Components 1 and 2 of the PCA explained $43 \%$ of the variance (component 1, $26.5 \%$; component 2, $16.9 \%$ ). Component 1 was mainly characterized by soil fertility motivations and agro-technical problems: It was positively correlated to "increasing organic matter" $(r=0.700)$ and "increasing biological soil quality" $(r=0.651)$. The problem of crop residues limiting sowing and emergence $(r=0.689)$, the lack of specific technical skills $(r=0.659)$ and limited available information $(r=0.649)$ were the main agro-technical challenges positively correlated with component 1 . Component 2 was mainly characterized by soil fertility motivations: "improving soil structure" ( $r=0.637)$, "limiting erosion crust formation" ( $r=$ $0.575)$ and "improving soil biological quality" $(r=0.565)$. Agrotechnical problems were negatively correlated to component 2 : "weed infestation" ( $r=-0.446)$, "adequacy of existing machines" and "high cost" $(r=-0.462)$ and "increasing labour requirements" $(r=-0.557)$. The hierarchical clustering provided three groups of farmers, characterized by their motivations and problems. Individuals from groups 1, 2 and 3 are respectively represented by circles, triangles and crosses. Ellipses are centred on the centroids of the groups, their width and height are given by the variances, and the slope of the main axis is the covariance 


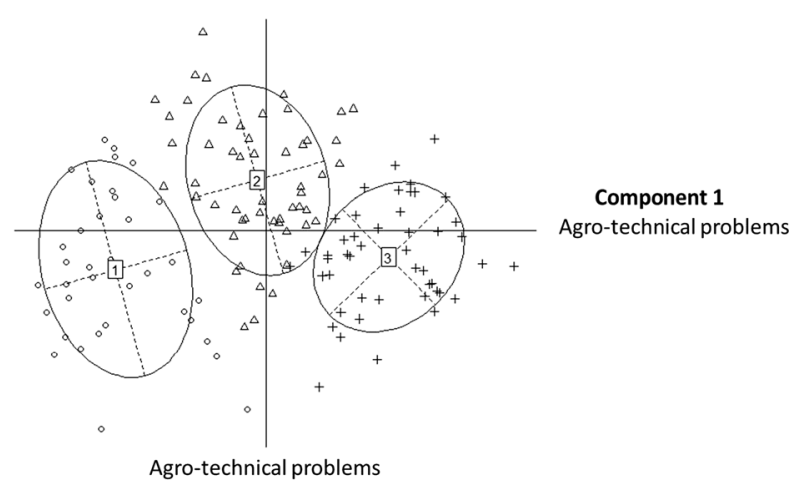

Fig. 4 Distribution and grouping of the 138 farmers using reduced tillage on the PCA map. Legend: Components 1 and 2 of the PCA explained $42 \%$ of the variance (component 1, $30.3 \%$; component 2, $12.1 \%$ ). Component 1 is mainly correlated to agro-technical problems: unstable/lower crop yields or crop failure $(r=0.806)$, weed infestation ( $r=0.792)$, destroying pasture/grass clover/alfalfa $(r=0.734)$ and lack of specific technical skills $(r=$ $0.721)$. Motivations such as improving yield $(r=-0.355)$ and limiting weeds, pests and diseases $(r=-0.451)$ are negatively correlated to component 1 . Component 2 was characterized

Whatever the practices (Figs. 3, 4 and 5), component 1 was positively correlated to agro-technical problems and component 2 was always positively correlated to soil fertility motivations. Because the groups are similarly displayed on the three PCA maps, there was consistency between the identified groups across practices.

We identified three types of attitudes of organic farmers applying conservation practices across Europe: "indifferent farmers" (group 1 in Figs. 3, 4 and 5), "soil conservationists" (group 2 in Figs. 3, 4 and 5) and "agro-technically challenged farmers" (group 3 in Figs. 3, 4 and 5). In order to compare the results across the practices, we summarize the main motivations and problems of the groups and supplementary variables in Table 1. Depending on the location of the group on the PCA maps and the significant relationship of supplementary variables with components 1 and 2, we deduced geographical and/or structural characteristics of the groups (Table 1).

Indifferent farmers were significantly less concerned by motivations and problems than other groups (Table 1). They may not have felt concerned by the motivations that were displayed in the survey. It is likely that those farmers did not feel specific problems for applying conservation practices, or they did not find adequate problems in the list provided in the mainly by soil fertility motivations: improving soil biological quality $(r=0.718)$, organic matter content $(r=0.648)$, soil structure $(r=0.563)$ and limiting erosion crust formation $(r=0.555)$. Component 2 was negatively correlated to increasing labour requirements $(r=-0.390)$ and residues limiting sowing and emergence $(r=-0.335)$. The hierarchical clustering provided three groups of farmers. Individuals from groups 1,2 and 3 are respectively represented by circles, triangles and crosses. Ellipses are centred on the centroids of the groups, their width and height are given by the variances, and the slope of the main axis is the covariance

questionnaire. Some farmers of this group mentioned "other" motivations and problems during their interviews, and these answers showed very site-specific interdependences. For instance in no-tillage, farmers were motivated by a no-tillage practice because their fields were very stony or they faced Fusarium wilt problems. They were both experienced with the reduced tillage practice (25 years of applying the practice on average, $\mathrm{SD}=12$ ) and converted to organic farming 17 years ago on average $(\mathrm{SD}=11)$ in case of green manure (Table 1$)$. This could explain that they mastered the practices and did not feel any specific problems. They were mainly located in the southern and the western regions of Europe, in areas of higher altitude than the overall mean of the sample. They used a low number of information channels about CA when applying reduced tillage. Two farms belonged to all three groups and applied the three conservation practices. There were six farmers in those groups, mainly located in France and Spain, and they applied green manure and reduced tillage.

Soil conservationist farmers shared a positive attitude and motivations regarding soil conservation (improving biological soil quality, structure and organic matter, and limiting soil erosion) and minimizing environmental impacts (Table 1). The groups were related to southern Europe and Spain in cases of no-tillage and green 
Component 2

Soil fertility motivations

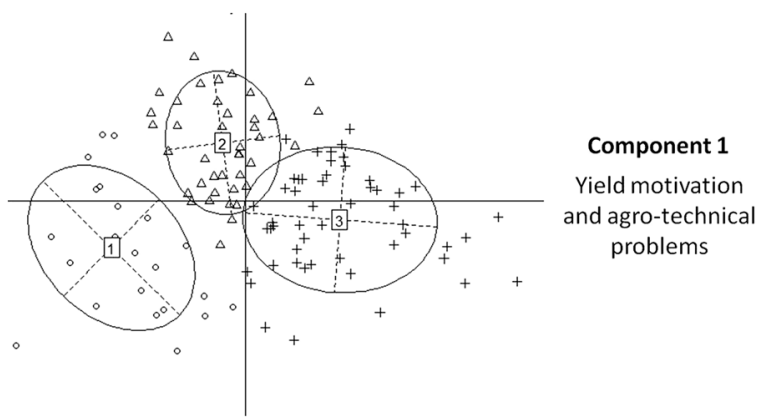

Fig. 5 Distribution and grouping of the 123 farmers using green manure on the PCA map. Legend: Components 1 and 2 of the PCA explained $34 \%$ of the variance. Component 1 was mainly correlated with improving yield $(r=0.665)$, followed by agrotechnical problems such as destroying green manure $(r=0.622)$, soil structure problems (e.g. compaction) $(r=0.621)$ and unfavourable establishment conditions $(r=0.618)$. Component 2 was mainly correlated to soil fertility motivations such as improving soil structure $(r=0.650)$, increasing on-farm nitrogen production $(r=0.618)$ and improving soil biological quality $(r=0.512)$. Agro-technical motivations and problems were negatively correlated to component 2, such as the lack of available $\mathrm{N}$ for nonleguminous green manures $(r=-0.379)$ and producing industrial crops, fuel crops, forage or seed crops $(r=-0.284)$. The hierarchical clustering provided three groups of farmers, characterized by their motivations and problems. Individuals from groups 1, 2 and 3 are respectively represented by circles, triangles and crosses. Ellipses are centred on the centroids of the groups, their width and height are given by the variances, and the slope of the main axis is the covariance

manure, while they were related to Switzerland for reduced tillage. Regarding challenges, farmers applying green manure faced increasing labour requirements. Such farmers were well connected to other farmers through networks in cases of reduced tillage (Table 1). Three farms belonged to all three groups and applied the three conservation practices. Sixteen farms belonged to the conservationist group, both for use of green manure and reduced tillage. Those farms were mainly located in France, Austria and Switzerland.

Agro-technically challenged farmers were more concerned by problems than by motivations (Table 1). These farmers are facing challenging agronomic conditions compared to other groups. In no-tillage, they expressed problems of increasing labour requirements, residues limiting sowing and emergence, limited nitrogen supply, and variable/lower crop yields or crop failure. They also expressed the need for more agronomic knowledge regarding using no-tillage in organic farming. In reduced tillage, they expressed problems of variable/lower crop yields or crop failure, residues limiting sowing and emergence, inadequacy of existing machines or high cost, weed infestation, lack of technical skills and problems when mixing residues and/or organic fertilizers. And, for green manure, they expressed problems of lack of technical skills, lack of available $\mathrm{N}$ for non-leguminous green manure, weed infestation and soil structure problems. They were motivated by advice from networks and neighbours. In cases of reduced tillage, the innovative challenge of applying such a practice, itself, served as a motivation. This expression of numerous problems might be explained by either more difficult agronomic conditions compared to other farmers (e.g. stony soils, droughts and short growing seasons as on high altitudes), or their difficulty to overcome the encountered problems (because of a lack of experience or inappropriate equipment, for example). Indeed, agro-technically challenged farmers were less skilled than the other groups with a lower number of years of experience with the reduced tillage practice (mean $=10, \mathrm{SD}=8$ ) and a more recent conversion in case of green manure $($ mean $=14, \mathrm{SD}=9$; Table 1$)$. In cases of reduced tillage, they used a wide range of information sources (Table 1). They often came from northern and eastern areas of Europe (e.g. Estonia), lowaltitude areas in particular (Table 1).

\section{Discussion}

Motivations and challenges of European organic farmers

\section{Organic farmers are mainly motivated by soil conservation}

Motivation for soil conservation always ranked within the first eight motivations, whatever the practice (Fig. 2). This result indicates that farmers are mainly concerned by soil conservation when applying conservation practices in organic farming. This result is consistent with the review by Knowler and Bradshaw (2007), which shows that one of the drivers for adopting conservation practices is awareness of soil fertility. Soil preservation usually becomes a key driver for farmers when they first experience soil problems (Lahmar 2010). Environmental motivations ranked 
Table 1 Summary of motivations and problems for "indifferent farmer," "soil conservationist" and agro-technically challenged" groups of no-tillage, reduced tillage and green manure (based on significant V-test results, $P<0.05$ )

\begin{tabular}{|c|c|c|c|}
\hline & No-tillage & Reduced tillage & Green manure \\
\hline \multicolumn{4}{|l|}{ "Indifferent farmer" groups } \\
\hline Number of farms & 8 & 36 & 30 \\
\hline Motivations & Less than other groups & Crop performance & Less than other groups \\
\hline Problems & Less than other groups & Less than other groups & Less than other groups \\
\hline Countries & - & - & Spain and Switzerland \\
\hline Coordinates & South and west & South and west & - \\
\hline Altitude & - & High altitude & High altitude \\
\hline Precipitation & - & Low rainfall & - \\
\hline Number of years since conversion & - & - & High \\
\hline $\begin{array}{l}\text { Number of years of experience with } \\
\text { the practice }\end{array}$ & - & High & - \\
\hline Information sources & - & Low number of sources for $\mathrm{CA}$ & - \\
\hline \multicolumn{4}{|l|}{ "Soil conservationist" groups } \\
\hline Number of farms & 21 & 54 & 41 \\
\hline Motivations & Soil conservation & Soil conservation & Soil conservation \\
\hline $\begin{array}{l}\text { Minimizing environmental impacts } \\
\text { and weeds, pests and diseases }\end{array}$ & Minimizing environmental impacts & Improving yields and on-farm $\mathrm{N}$ & \\
\hline Problems & $\begin{array}{l}\text { Not concerned or less than other } \\
\text { groups }\end{array}$ & $\begin{array}{l}\text { Less than other groups or not } \\
\text { concerned }\end{array}$ & $\begin{array}{l}\text { Increasing labour requirements } \\
\text { and costs of seeds, or less } \\
\text { than other groups }\end{array}$ \\
\hline Countries & Italy and Spain & Switzerland & Spain \\
\hline Coordinates & - & - & South \\
\hline Altitude & - & - & High \\
\hline Number of years since conversion & & & Medium \\
\hline $\begin{array}{l}\text { Number of years of experience with } \\
\text { the practice }\end{array}$ & - & Medium & - \\
\hline Information sources & - & Belonging to CA networks & - \\
\hline \multicolumn{4}{|l|}{ "Agro-technically challenged" groups } \\
\hline Number of farms & 11 & 48 & 52 \\
\hline Motivations & Not concerned by any motivation & Technical challenge & Technical challenge \\
\hline Problems & All problems & $\begin{array}{l}\text { Biodiversity and soil structure } \\
\text { All problems } \\
\text { labour requirements }\end{array}$ & $\begin{array}{l}\text { Almost all motivations } \\
\text { All problems, except }\end{array}$ \\
\hline Countries & Estonia & - & Ireland \\
\hline Coordinates & East and north & East and north & - \\
\hline Altitude & - & Low altitude & Low altitude \\
\hline Precipitation & - & High rainfall & - \\
\hline Number of years since conversion & - & - & Low \\
\hline $\begin{array}{l}\text { Number of years of experience with } \\
\text { the practice }\end{array}$ & - & Low & - \\
\hline Information sources & - & High number of sources for CA & - \\
\hline
\end{tabular}

Main supplementary variables are displayed when available

$C A$ conservation agriculture

lower on the list, whatever the practice, showing they were considered secondary motivations compared to soil fertility (Fig. 2).
Cost reduction (by limiting fuel and machinery) and saving labour time are important motivations in conventional agriculture (Lahmar 2010; Soane et al. 2012). 
Organic farmers of our study actually experienced increased labour requirements and inadequacy of machinery when analyzing the three conservation practices together (no-tillage, reduced tillage and green manure, Fig. 2). Increased labour requirements are mainly explained by the increased number of mechanical weeding operations. Even if stopping ploughing helps reducing fuel cost and labour time, the increased number of mechanical weeding operations and the shallow soil tillage operations might counterbalance this benefit. Thus, cost reduction is not one of the major motivations of organic farmers applying reduced tillage. Nevertheless, reduced costs were one of the most important motivations for no-tillage (fourth ranking). This is due to the labour and fuel savings induced by stopping tillage practices. The inadequacy of machinery mainly refers to the destruction of cover crops and seeding the next crop. Destroying the green manure in organic farming is crucial for sowing the next crop in good conditions. Because of the ban of herbicides, organic farmers rely only on mechanical equipment such as roller-crimper (which is used only by $2 \%$ of the famers of our sample) to destroy green manures. Such machinery is still quite scarce in Europe and more research is need for its adoption (Peigné et al. 2007). New machinery is being currently developed by organic farmers to scalp green manure roots such as Eco-Dyn which is a direct seeder associated with duck-foot tines. When the green manure is not correctly destroyed, the use of direct seeder is hampered.

Agronomic improvements like weed, pest and disease control ranked particularly high for green manure in our study. This result is unexpected when compared with studies on conventional agriculture. As the ban on chemical inputs reduces the technical options for controlling weeds, pests and diseases in organic farming, green manure application (e.g. intercropping and mulching) offers a strategy to cover the soil and compete with weeds. It is also an opportunity to adopt a resource dilution strategy at the field scale (e.g. intercropping), or to disrupt pest and disease cycles (e.g. cover cropping). Resource dilution refers to the hypothesis that it is easier for a pest to become abundant when the resources it uses are concentrated in a unique crop than when the resources are diluted with non-host plants.
Further challenges for conservation agriculture in organic farming in Europe

No-tillage faces the most technical limits when compared to green manure and reduced tillage in organic farming: inadequate machinery, limited information and lack of specific skills. We showed that the lack of specific skills and information was a pivotal problem in cases of no-tillage, while it ranked almost last on the reduced tillage list. This is mainly explained by the innovativeness of no-tillage practices. Indeed, as previously shown both in conventional (Knowler and Bradshaw 2007) and organic studies, there is a lack of technical and scientific references concerning conservation practices, especially for no-tillage practices in organic farming (Carr et al. 2013).

In conventional agriculture, conservation practices are known to be very knowledge intensive (Giller et al. 2009) because they require rethinking the whole system (Lahmar 2010). This systemic rethinking is also the basis of organic farming principles. Thus, organic farmers are usually skilled at redesigning their system with a holistic management of the farm. Nevertheless, similarly to conventional agriculture, the effect of conservation practices in organic farming could be different from what farmers expected with regard to their knowledge and experience. This might lead to an overestimation of the problems by the farmers. Here, in the case of organic farming, the group of agro-technically challenged farmers might have been experiencing such difficulties and strongly expressing problems they encountered.

Consequently, there is a need for adequate support networks and technical advice: stakeholders, farmers, researchers and extension agents (Giller et al. 2009; Lahmar 2010), especially under organic European conditions where knowledge is even scarcer. Our study shows that farmers are using multiple networks and sources of information for conservation agriculture and organic farming. Moreover, we know that at the time of the survey, there were no specialized networks that specifically address conservation practices under organic conditions in the surveyed countries. Moreover, advice from networks and neighbours always ranked very low on the list of motivations, no matter the practice (Fig. 2). The first hypothesis could be that the surveyed farmers do not communicate much with the neighbours even if the latter are applying organic and/or conservation agriculture. The second and more likely hypothesis 
could be that European organic farmers applying conservation practices are pioneers and thus geographically isolated from other farmers combining organic farming and conservation agriculture, similarly to conventional farmers who gave up ploughing in pioneer stages (Soane et al. 2012).

Weed infestation and management, and destruction of the preceding crop or green manure were common agronomic challenges for all practices (Fig. 2). However, such problems ranked higher in cases of notillage and reduced tillage practices compared to green manure. Weed control is often considered a strong technical constraint to the application of conservation practices in organic farming (Berner et al. 2008; Sans et al. 2011). Unlike conventional conservation agriculture (Lahmar 2010; Soane et al. 2012), there is no increase in herbicide use, but mechanical weeding might incur higher labour and energy costs (Peigné et al. 2007).

The inadequacy of existing machinery and their high cost were strong constraints (Fig. 2) for no-tillage and reduced tillage under organic conditions, similar to conventional studies (Derpsch et al. 2010). Unlike in conventional farming where larger farms seem to take more risks (Lahmar 2010), farmers from our survey own farms that ranged from small $(<50 \mathrm{ha})$ to large ( $>100 \mathrm{ha}$ ), showing no specific adoption pattern linked to farm size. Adoption of conservation practices by organic farmers does not seem to be an opportunistic behaviour as the constraints were strong and numerous, and associated benefits are only visible in the long term.

Socio-economic problems such as cost of seeds and increasing labour requirements seem to be strong constraints in applying green manures. Agronomic problems are related to the technical application of the practice (e.g. destroying green manure, and unfavourable establishment conditions).

Organic farmers' attitudes towards conservation agriculture

Our results show that the combination of motivations and problems led to three different attitudes among interviewed organic farmers. Indifferent farmers do not feel specific problems related to applying conservation practices, or they do not find adequate problems in the list provided in the questionnaire. The green manure group had been organic for a long time and the reduced tillage group had been experiencing reduced tillage for a long time, which might explain why they mastered their practices and thus encountered fewer problems than other groups. The reduced number of information sources that they used for conservation agriculture (in cases of reduced tillage) also shows that they were autonomous farmers. Soil conservationist farmers were mainly interested in soil preservation. Those using green manure were also motivated by improving yields. This motivation could be the final aim of soil conservation, as stated in Soane et al. (2012). The farmers were less concerned than other groups by problems, showing their enthusiasm for conservation agriculture. Those farmers were committed to conservation agriculture and shared environmental stewardship (Reimer et al. 2011): They might feel responsible for preserving or improving soil fertility. Agro-technically challenged farmers expressed that good agronomic conditions and crop management are difficult to achieve. The lack of technical skills was always significantly correlated with this type of farmer, whatever the practice they applied. Moreover, in case of green manure, agro-technically challenged farmers were less experienced in organic farming, and in case of reduced tillage, they were less experienced with the practice (Table 1), explaining why they could feel not skilled enough for applying conservation practices. In order to cope with this problem, in cases of reduced tillage, they used a wide range of information sources. Farmers using green manure were recently converted to organic farming, which might explain the technical challenges they faced.

These three attitudes were related to the location of farms in cases of indifferent farmers and agrotechnically challenged farmers. Indeed, due to specific conditions related to the location of the farms (altitude, precipitation and country), some farmers might have experienced specific constraints that explain their motivations and problems. For example, indifferent farmers were mainly located in south-western Europe, with high altitudes and low rainfall. Such farmers did not feel concerned by the proposed motivations and problems of the questionnaire. This might also show the limitations of our questionnaire in covering the range of perceptions of organic farmers. Soil conservationist Spanish farmers seem to have relied on both no-tillage and green manure to preserve their soils, while in Switzerland, soil conservationists applied reduced tillage. Despite the climatic constraints of southern Europe to using green manure, when farmers were strongly motivated by soil conservation, they did apply it. Indeed, green manure soil conservationists were 
significantly located in the south, where green manure was less applied. Agro-technically challenged farmers were located in low-altitude rainy areas of eastern and northern Europe (e.g. Estonia). This shows that applying conservation practices in these areas could be very technically challenging. Whatever the location of farmers, they could be either soil conservationists or agrotechnically challenged, meaning that the main driver of their motivations and problems was more dependent on their personal environmental attitudes and beliefs than on their farm location and/or associated cultural characteristics.

\section{Conclusion}

This study provides new knowledge on the motivations and problems that European organic farmers face when applying conservation practices. We showed that because of the pedoclimatic conditions, green manure and no-tillage were more frequent in the northern part of Europe while reduced tillage was more frequent in the southern part of Europe. We showed that major motivations and problems and their rankings were similar for reduced and no-tillage. Organic farmers are highly motivated by soil conservation (i.e. improving soil biological quality, soil structure and soil organic matter) when adopting conservation practices. We showed that there are similarities in farmer attitudes towards applying notillage, reduced tillage and green manure. We identified two contrasting farmer attitudes: soil conservationists and agro-technically challenged farmers. Soil conservationists expressed strong motivation for soil preservation (improving biological soil quality, structure and organic matter, as well as limiting soil erosion). Agrotechnically challenged farmers expressed agronomic problems and challenges. However, there is no clear pattern that would explain the grouping related to pedo-climatic conditions or farm characteristics. Indeed, the application and perception of conservation practices differed across Europe.

This study confirms the need for research concerning conservation practices in organic farming. As farmers are mainly motivated by soil conservation, researchers should first and foremost address the following question: Do conservation practices really improve soil preservation? As weeds have been identified as the most important problem for applying reduced and no-tillage, researchers should explore the technical options for coping with weed infestation. Finally, as destroying the preceding crop or green manure was also a major problem whatever the practice, researchers should propose and test innovative practices for efficiently eliminating crops and green manure and reach good crop establishment conditions. Addressing those issues should help strengthen farmers' motivations for CA and should help further adoption and development of conservation agriculture among organic farmers. This study also showed that farmers' perceptions vary within the studied sample, leading to different farmers' groups. Researchers should keep this diversity in mind in order to test and propose adequate cropping systems, which could be different, depending on the targeted group. Further understanding of the diversity of practices would be interesting to test and tune innovative conservation cropping systems in organic farming.

Acknowledgments This research was supported by CORE Organic II Funding Bodies, being partners of the FP7 ERANet (www.coreorganic2.org), in the framework of TILMAN-ORG project (www.tilman-org.net). The authors would like to thank Mathieu Guérin, Monica Stanica-Negrescu, Teatske Bakker, Anne Brogi, Lisa Nilles, Rethy Katalin and European interviewed farmers.

Compliance with ethical standards Marion Casagrande, Joséphine Peigné, Vincent Payet, Paul Mäder, F.Xavier Sans, José Manuel Blanco-Moreno, Daniele Antichi, Paolo Bàarberi, Annelies Beeckman, Frederica Bigongiali, Julia Cooper, Hansueli Dierauer, Kate Gascoyne, Meike Grosse, Juergen Heß, Andreas Kanzler, Anne Luik, Elen Peetsmann, Koen Willekens and Christophe David declare that they have no conflict of interest.

\section{References}

Bàrberi P (2002) Weed management in organic agriculture: are we addressing the right issues? Weed Res 42:177-193. doi:10. 1046/j.1365-3180.2002.00277.x

Berner A, Hildermann I, Fliessbach A, Pfiffner L, Niggli U, Mader P (2008) Crop yield and soil fertility response to reduced tillage under organic management. Soil Till Res 101:89-96. doi:10.1016/j.still.2008.07.012

Carr P, Gramig G, Liebig M (2013) Impacts of organic zero tillage systems on crops, weeds, and soil quality. Sustain 5:31723201. doi: $10.3390 /$ su5073172

Darnhofer I, Schneeberger W, Freyer B (2005) Converting or not converting to organic farming in Austria: farmer types and their rationale. Agric Hum Values 22:39-52. doi:10.1007/ s10460-004-7229-9

Derpsch R, Friedrich T, Kassam A, Hongwen L (2010) Current status of adoption of no-till farming in the world and some of its main benefits. Int J Agric Biol Eng 3:1-25. doi:10.3965/j. issn.1934-6344.2010.01.001-025 
Giller KE, Witter E, Corbeels M, Tittonell P (2009) Conservation agriculture and smallholder farming in Africa: the heretics' view. Field Crop Res 114:23-34. doi:10.1016/j.fcr.2009.06.017

Greiner R, Patterson L, Miller O (2009) Motivations, risk perceptions and adoption of conservation practices by farmers. Agric Syst 99:86-104. doi:10.1016/j.agsy.2008.10.003

Hobbs PR, Sayre K, Gupta R (2008) The role of conservation agriculture in sustainable agriculture. Philos Trans R Soc Lond B Biol Sci 363(1491):543-55. doi:10.1098/rstb.2007. 2169

Kassam A, Friedrich T, Shaxson F, Pretty J (2009) The spread of conservation agriculture: justification, sustainability and uptake. Int J Agric Sustain 7(4):292-320. doi:10.3763/ijas. 2009.0477

Knowler D, Bradshaw B (2007) Farmers' adoption of conservation agriculture: a review and synthesis of recent research. Food Policy 32:25-48. doi:10.1016/j.foodpol.2006.01.003

Kuntz M, Berner A, Gattinger A, Scholberg JM, Mäder P, Pfiffner L (2013) Influence of reduced tillage on earthworm and microbial communities under organic arable farming. Pedobiologia 56:251-260

Lahmar R (2010) Adoption of conservation agriculture in Europe. Land Use Policy 27:4-10. doi:10.1016/j.landusepol.2008.02. 001

Lê S, Josse J, Husson F (2008) FactoMineR: an R package for multivariate analysis. J Stat Softw 25:1-18

Lefèvre V, Capitaine M, Peigné J, Roger-Estrade J (2012) Soil conservation practices in organic farming: overview of French farmers' experiences and contribution to future cropping systems design. In: Proceedings of the 10th European IFSA Symposium, Aarhus, Denmark (http://ifsa. boku.ac.at/cms/fileadmin/Proceeding2012/IFSA2012_WS6. 3_Lefevre.pdf)

Leifeld J (2012) How sustainable is organic farming? Agric Ecosyst Environ 150:121-122. doi:10.1016/j.agee.2012.01.020

Mäder P, Berner A (2011) Development of reduced tillage systems in organic farming in Europe. Renew Agric Food Syst 27:711. doi:10.1017/S1742170511000470

Peigné J, Ball BC, Roger-Estrade J, David C (2007) Is conservation tillage suitable for organic farming? A review. Soil Use Manag 23:129-144. doi:10.1111/j.1475-2743.2006.00082.x
R Core Team. (2012) R: A language and environment for statistical computing. Edited by R Foundation for Statistical Computing. Vienna, Austria

Reimer AP, Thompson AW, Prokopy LS (2011) The multidimensional nature of environmental attitudes among farmers in Indiana: implications for conservation adoption. Agric Hum Values 29(1):29-40. doi:10.1007/ s10460-011-9308-z

Sans FX, Berner A, Armengot L, Mäder P (2011) Tillage effects on weed communities in an organic winter wheat-sunflowerspelt cropping sequence. Weed Res 51:413-421. doi:10. 1111/j.1365-3180.2011.00859.x

Schneider F, Fry P, Ledermann T, Rist S (2009) Social learning processes in Swiss soil protection - the "from farmer - to farmer" project. Hum Ecol 37:475-489. doi:10.1007/ s10745-009-9262-1

Schneider F, Steiger D, Ledermann T, Fry P, Rist S (2012) Notillage farming: co-creation of innovation through network building. Land Degrad Dev 23:242-255. doi:10.1002/ldr. 1073

Soane BD, Ball BC, Arvidsson J, Basch G, Moreno F, RogerEstrade J (2012) No-till in northern, western and southwestern Europe: a review of problems and opportunities for crop production and the environment. Soil Till Res 118:6687. doi:10.1016/j.still.2011.10.015

Teasdale JR, Coffman CB, Mangum RW (2007) Potential longterm benefits of no-tillage and organic cropping systems for grain production and soil improvement. Agron J 99:12971305. doi:10.2134/agronj2006.0362

Thioulouse J, Chessel D, Dolédec S, Olivier JM (1997) ADE-4: a multivariate analysis and graphical display software. Stat Comput 7:75-83

Vakali C, Zaller JG, Köpke U (2011) Reduced tillage effects on soil properties and growth of cereals and associated weeds under organic farming. Soil Till Res 111:133-141. doi:10. 1016/j.still.2010.09.003

Yiridoe EK, Odwa D, Atari A, Gordon R, Smale S (2010) Factors influencing participation in the Nova Scotia Environmental Farm Plan Program. Land Use Policy 27:1097-1106. doi:10. 1016/j.landusepol.2010.02.006 